\title{
Apresentação
}

\section{Solo, da origem da vida ao alicerce das civilizações: uso, manejo e gestão}

\author{
Daniel Vidal Pérez ${ }^{(1)}$, Maria de Lourdes Mendonça Brefin ${ }^{(1)}$, José Carlos Polidoro(1)
}

(1)Embrapa Solos, Rua Jardim Botânico, n. 1.024, CEP 22460-000, Rio de Janeiro, RJ, Brasil. E-mail: daniel.perez@embrapa.br, lourdes.mendonca@embrapa.br, jose.polidoro@embrapa.br

As raízes da ciência do solo vão fundo na história humana. Apesar de nossos mais distantes ancestrais encontrarem sua comida por coleta e caça, eles dependiam indiretamente dos solos, para apoiar o crescimento das plantas comestíveis e das plantas que guiavam a migração dos animais que caçavam.

Com a transição para a agricultura, a dependência humana e seu impacto sobre o solo tornaram-se mais diretos e mais evidentes, tendo sido até entronizados em sua vida religiosa/espiritual. Pela mitologia chinesa, $\mathrm{Nu}$ Wa, a Serpente Criadora da Humanidade, criou o ser humano (ren) a partir do barro amarelo. Pela mitologia suméria, os deuses Enlil e Enki criaram o homem e a mulher a partir do barro. Pelos gregos, foi Prometeu quem moldou do barro uma criatura à imagem e semelhança dos deuses e soprou em seu corpo o sopro da vida. A mitologia iorubá indica que foi o orixá Obatalá quem criou a raça humana com o barro oferecido pela orixá Nanã. Segundo a mitologia tupi-guarani, Tupã formou estátuas de argila do homem e da mulher. E mesmo na história mais recente do homem, essa crença de criação permanece. Pelo Catolicismo temse: "Então o Senhor Deus formou o homem do pó da terra e soprou em suas narinas o fôlego de vida, e o homem se tornou um ser vivente" (Bíblia, Gênesis 2: 7). E para os muçulmanos: "Criamos o homem de argila, de barro modelável" (Alcorão Sagrado - Surata 15, AL HIJR, versículo, 26). Interessante observar que, de certo modo, a ciência moderna corrobora em parte essa tese, à medida que sugere que a vida pode ter-se iniciado em superfícies de minerais de argila tipicamente encontrados no desenvolvimento dos solos (Hanczyk et al., 2003; Ricardo \& Szostak, 2009).

Como se já não bastasse sua importância nos primórdios da vida humana, a História nos mostra, por diversas vezes, a íntima relação do solo com o surgimento de civilizações e povos ao longo de nossa jornada na Terra. Comecemos com o Egito, um dos primeiros agrupamentos humanos com organização de nação, cujo nome, segundo alguns estudiosos, deriva da palavra Kmt, que significa povo da terra preta, em alusão à cor do solo após as inundações do rio Nilo que fertilizavam a terra. Nessa mesma época, surgiram, também, diversos povos em uma região próxima - a Mesopotâmia -, um planalto que se erguia entre os rios Tigre e Eufrates, também conhecido como Crescente Fértil, por ter o formato de uma lua crescente e de ter um solo fértil. Caminhando alguns milênios, pode-se relacionar a origem dos Estados Unidos da América ao conhecimento do solo, já que essa informação foi crucial na devastadora derrota britânica na batalha de Cowpens (1781), o que determinou uma reviravolta definitiva na guerra de independência das 13 colônias americanas.

Além desses fatos pitorescos, é certo que o manejo do solo repercutiu ao longo da nossa história, em maior ou menor grau, com a ascensão e queda de diversas civilizações. McNeill1 \& Winiwarter (2004) e Diamond (2005) são exemplos de autores que apontam como diversos povos, desde o Novo Mundo até a China, utilizaram seu solo para produzir alimentos e, assim, se estabelecerem como nação. Aqueles que desenvolveram técnicas de manejo de solo, em resposta à depleção de nutrientes ou à degradação ecológica provocada pelo desmatamento e a erosão, floresceram. Os que não conseguiram sucesso entraram em decadência. Tomemos como exemplo a derrocada da nação Maia, que ocorreu bem antes da chegada dos espanhóis à América. Acredita-se que a associação de três fatores intrinsecamente relacionados levou à queda 
dos maias: o aumento do desmatamento para a criação de áreas agrícolas, a diminuição da pluviosidade e o mau uso do solo (erosão), que diminuíram a capacidade de suporte dos principais centros urbanos.

O amadurecimento da ciência do solo como um campo distinto requereu progressos científicos em áreas relacionadas, tais como química, física, biologia, geografia e geologia. Por isso, ela só se estabeleceu tardiamente, no final do século XIX, a partir dos trabalhos pioneiros de pesquisadores russos, com destaque para Dokuchaev. E, exatamente, por conta dessa abordagem interdisciplinar, a ciência do solo, viu-se precocemente ameaçada pela intensiva especialização e fragmentação da disciplina Solo, nas décadas de 1980 e 1990, contrariando a visão original de estudá-lo como um corpo natural que faz parte da paisagem. Em razão disso, certos autores como Basher (1997), White (1997) e Baveye et al. (2006) manifestaram um grande pessimismo quanto ao futuro do solo como ciência independente e não um ramo da agronomia.

O interesse mais recente em temas como mudanças climáticas (gases de efeito estufa), produção sustentável de alimentos, biocombustíveis, controle da erosão, problemas de esgotamento de nutrientes, relação saúde dos solos e saúde humana e as preocupações ambientais trouxeram novamente a ciência do solo ao centro de discussões internacionais. Isto ocorre porque a ciência do solo é capaz de servir de ponte entre outras disciplinas e esferas do conhecimento (Figura 1).

Neste contexto, vários países e organismos internacionais iniciaram o século 21 preocupados com a temática de solos. Todos foram unânimes em considerá-lo um recurso vital, não renovável na escala humana, e que está cada vez mais sob pressão antrópica, o que representa um risco para a continuidade de nossa sociedade. Nessa situação, destacam-se duas ações. Primeiro, a dos países europeus que, em 2002, emitiram seu primeiro comunicado tocando no tema de proteção do solo, criando as bases para suas diretivas e políticas ambientais futuras (European Commission, 2002). Depois, em junho de 2013, em Assembleia Geral realizada na sede da FAO em Roma, lançaramse as bases para a formação de uma parceria global de solos, com a finalidade de aumentar o apoio mundial para a gestão sustentável do solo (FAO, 2016a). Neste contexto, estabeleceu-se a figura de um Painel Intergovernamental Técnico de Solos (FAO, 2016b), que assumiu o vácuo que havia de uma autoridade global para fornecer pareceres científicos e técnicos sobre os recursos do solo, de forma a contribuir para a agenda global de desenvolvimento sustentável. Todas essas ações culminaram em uma resolução da própria Organização das Nações Unidas que, em sua Assembleia Geral de 20 de dezembro de 2013 (A/ RES/68/232), institucionalizou o dia 5 de dezembro e o ano de 2015 como, respectivamente, o Dia Mundial e o Ano Internacional do Solo, de modo a reconhecer a necessidade urgente, em todos os níveis, de aumentar a conscientização e a promoção da sustentabilidade do recurso solo (United Nations, 2016).

E no Brasil? Recentemente, após coordenar a realização do primeiro evento sobre governança do solo no País, juntamente com a Embrapa e outras instituições parceiras, o Tribunal de Contas da União (TCU, 2015a) apontou que a insuficiência de informações e a dificuldade de acesso a dados de solos, em razão da inexistência de um sistema de dados único ou de uma plataforma - que permita a interpretação desses dados, por profissionais que necessitam desse tipo de informação -, são fatores que comprometem o planejamento, a execução e o monitoramento das políticas públicas para o uso sustentável da terra em atividades agropecuárias e florestais. Além disso, o TCU destaca as deficiências de ordem legal decorrentes da complexidade e dispersão da legislação brasileira, assim como a sobreposição e dissociação das legislações de solo e água. Com base nessas ocorrências, foi firmado um acórdão (TCU, 2015b) que, entre outras providências, determina a inclusão no próximo plano plurianual (PPA) de um Programa Nacional de Levantamento e Interpretação de Solos, bem como recomenda ao Ministério da Agricultura, Pecuária e Abastecimento (MAPA) e à Empresa Brasileira de Pesquisa Agropecuária (Embrapa) que estabeleçam mecanismos colaborativos e permanentes para a organização, sistematização e operacionalidade de dados decorrentes de levantamento de solos do Brasil.

É dentro deste espírito de busca de novos caminhos e sistematização de novas informações para estudar e compreender os solos brasileiros que este Número Temático, da revista Pesquisa Agropecuária Brasileira (PAB), se insere.

Editada sob a égide da Empresa Brasileira de Pesquisa Agropecuária (Embrapa) e subordinada ao seu Serviço 
de Informação Científica e Tecnológica, a PAB acolhe, neste Número Temático, artigos técnico-científicos inéditos e originais, que abrangem as principais linhas de Pesquisa, Desenvolvimento e Inovação ligadas ao tema "Solo como fator de integração entre os componentes ambientais e a produção agropecuária" e áreas afins, acompanhando as atividades e eventos comemorativos do Ano Internacional de Solos promovidos pela Organização das Nações Unidas/ Organização das Nações Unidas para a Alimentação e a Agricultura (ONU/FAO).

Esta iniciativa foi adotada tendo em vista o estado de desenvolvimento do tema, sua relevância e a evolução científica e tecnológica que atualmente se observam nas diversas subáreas da Ciência do Solo, intensificados pela exigência cada vez mais alta de competitividade e sustentabilidade da agropecuária brasileira. Dentro deste conjunto, pretende-se ressaltar o estado atual e a recente evolução das demandas e do conhecimento sobre o solo como fator integrador das diversas esferas físicas e biológicas que compõem o ambiente superficial do planeta Terra: litosfera, biosfera, atmosfera, hidrosfera.

Neste número temático, são priorizadas as seguintes vertentes principais: Solo x Planejamento, Solo x Produção e Solo x Ambiente.

No que se refere ao planejamento do uso da terra, estão as contribuições sobre a caracterização dos solos e o uso de resultados, métodos e ferramentas da geotecnologia para subsidiar subáreas, como: a classificação de solos; a caracterização e o mapeamento digital de solos; a agricultura de precisão; os zoneamentos de componentes ambientais, isolados ou em conjunto; e modelos que orientem a sustentabilidade da produção agropecuária.

$\mathrm{Na}$ vertente Solo e Produção, abordaram-se temas como: os sistemas conservacionistas de manejo e seus impactos sobre a qualidade do solo e da água; a

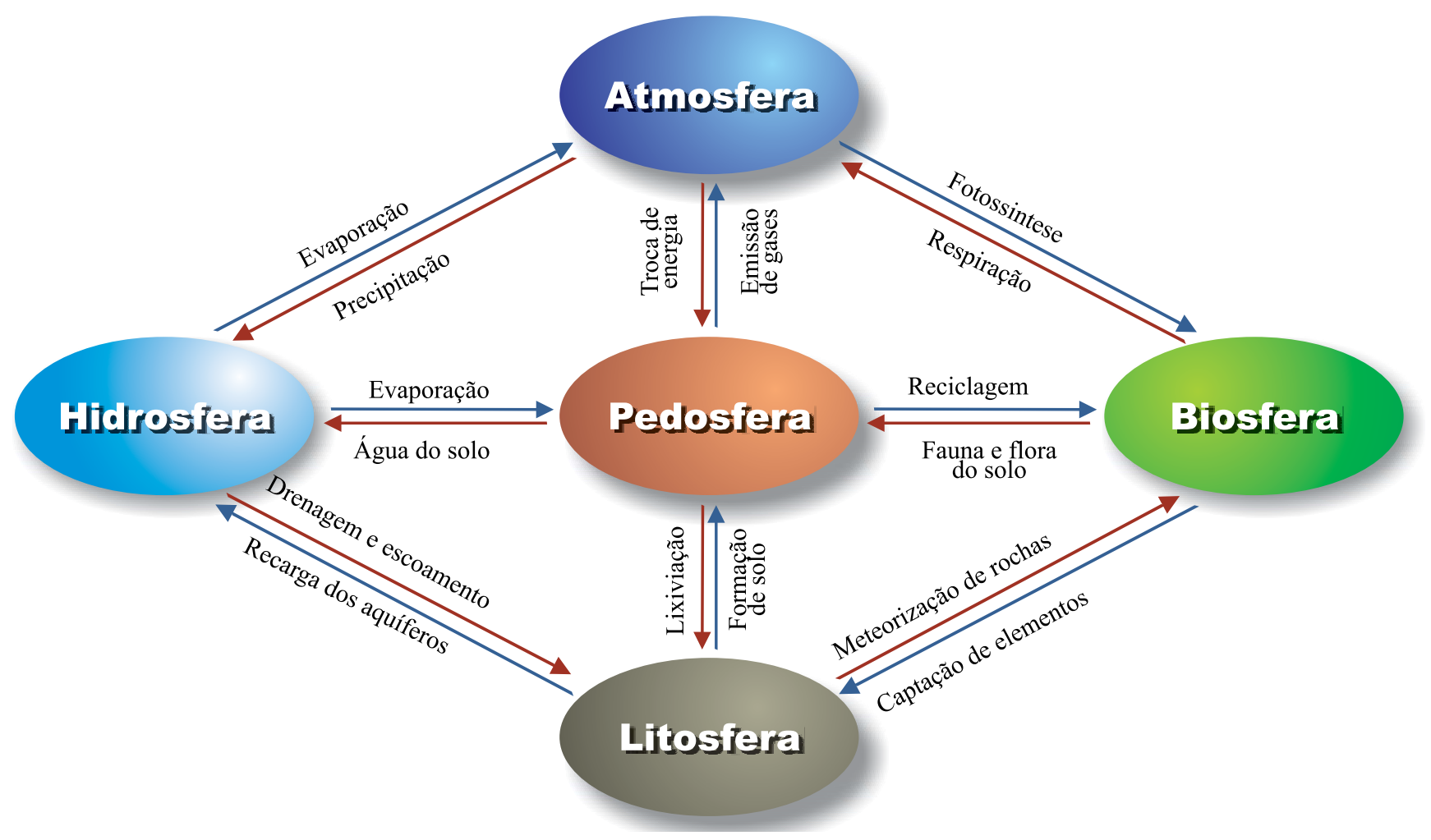

Figura 1. Processos interativos do relacionamento da pedosfera com a biosfera, atmosfera, hidrosfera e litosfera. Fonte: adaptado de Lal et al. (1998). 
quantificação dos efeitos dos sistemas de manejo sobre a qualidade e a conservação do solo e da água; e a tropicalização de fertilizantes e seus impactos sobre a produção agropecuária.

Finalmente, na vertente Solo e Ambiente, estão as seguintes contribuições: o solo e os serviços ambientais; o papel do solo no funcionamento da paisagem; e o impacto de ações antrópicas sobre o provimento e a manutenção de serviços ambientais.

\section{Referências}

BASHER, L.R. Is pedology dead and buried? Australian Journal of Soil Research, v.35, p.979-994, 1997. DOI: 10.1071/S96110.

BAVEYE, P.; JACOBSON, A.R.; ALLAIRE, S.E.; TANDARICH, J.P.; BRYANT, R.B. Whither goes soil science in the United States and Canada? Soil Science, v.171, p.501-518, 2006. DOI: 10.1097/01.ss.0000228032.26905.a9.

COMMISSION EUROPEAN. Communication from the Commission to the Council, the European Parliament, the Economic and Social Committee and the Committee of the Regions - Towards a Thematic Strategy for Soil Protection, COM/2002/0179 final*/. Brussels, 2002. Disponível em: <http://eur-lex.europa.eu/legal-content/EN/ TXT/?uri=celex:52002DC0179>. Acesso em: 28 set. 2016.

DIAMOND, J. Collapse: how societies choose to fail or succeed. Penguin: New York, 2005. 608p.

FAO. Food and Agriculture Organization of the United Nations. Global Soil Partnership. Disponível em: <http:/www.fao.org/ global-soil-partnership/en/>. Acesso em: 28 set. 2016a.

FAO. Food and Agriculture Organization of the United Nations. Intergovernmental Technical Panel on Soils. Disponível em:
$<$ http://www.fao.org/global-soil-partnership/intergovernmental-technical-panel-soils/en/>. Acesso em: 28 set. $2016 \mathrm{~b}$.

HANCZYC, M.M; FUJIKAWA, S.M.; SZOSTAK, J.W. Experimental models of primitive cellular compartments: encapsulation, growth, and division. Science, v.302, p.618-622, 2003. DOI: $10.1126 /$ science. 1089904.

LAL, R.; KIMBLE, J.; FOLLETT, R. Pedospheric processes and the carbon cycle. In: LAL, R.; KIMBLE, J.; FOLLETT, R.F.; STEWART, B.A. (Ed.). Soil processes and the carbon cycle. Boca Raton: CRC Press, 1998. p.1- 8.

MCNEILL, J. R.; WINIWARTER, V. Breaking the sod: humankind, history, and soil. Science, v.304, p.1627-1629, 2004. DOI: 10.1126/ science. 1099893.

RICARDO, A.; SZOSTAK, J.W. Origem da vida na terra. Scientific American Brasil, v.89, p.38-47, 2009.

TCU. TRIBUNAL DE CONTAS DA UNIÃO. TC 011.713/2015-1. 2015a. Relatório de auditoria. Disponível em: <http://portal3. tcu.gov.br/portal/page/portal/TCU/imprensa/noticias/noticias arquivos/011.713-2015-1\%20MAPA\%20E\%20MMA\%20 solos\%20comp.pdf $>$. Acesso em: 27 set. 2016.

TCU. TRIBUNAL DE CONTAS DA UNIÃO. Acórdão 1942, de 5 de agosto de 2015. 2015b. Disponível em: <https://contas. tcu.gov.br/juris/Web/Juris/ConsultarTextual2/Jurisprudencia.s? colegiado $=$ PLENARIO\&numeroAcordao $=1942 \&$ ano Acordao $=2015>$. Acesso em: 28 set. 2016.

UNITED NATIONS. General Assembly. Resolution adopted by the General Assembly on 20 December 2013 [on the report of the Second Committee (A/68/444)]. A/RES/68/232. World Soil Day and International Year of Soils. Disponível em: <http://www.un.org/en/ga/search/view_doc. asp?symbol=A/RES/68/232>. Acesso em: 27 set. 2016.

WHITE, R.E. Soil science: raising the profile. Australian Journal of Soil Research, v.35, p.961-978, 1997. DOI: 10.1071/S96090. 